\title{
Properties of catalyst for iron and manganese oxidation in filter materials
}

\author{
Joanna Jeż-Walkowiak ${ }^{1, *}$, Małgorzata Komorowska-Kaufman ${ }^{1}$, Zbysław Dymaczewski ${ }^{1}$, Marek M. Sozański ${ }^{1}$, and \\ Przemysław Zakrzewski ${ }^{2}$ \\ ${ }^{1}$ Poznan University of Technology, Institute of Environmental Engineering, 61-131 Poznań, ul. Berdychowo 4, Poland \\ ${ }^{2}$ Poznan University of Technology, Institute of Computing Science, 61-131 Poznań, ul. Piotrowo 2, Poland
}

\begin{abstract}
The aim of this work is to determine the properties of contact layers of grain of different type of filter media in term of their suitability for catalytical manganese oxidation and auto-activation for manganese removal from groundwater. The following oxidative filtration materials were investigated: autoactivated silica sand taken from full-scale filters (oxide coated filter media), Pyrolox - manganese ore natural material and Hydrolit - artificially activated material. As a reference two natural not chemically active materials were tested: clean silica sand and clean chalcedonite. The investigation resulted in chemical composition and microstructure parameters of catalyst contact layers of grains. The modern analytical methods were used: EDAX, Raman spectroscopy, mercury and helium porozymetry. The data indicated that catalyst from autoacivated filtration material has better chemical composition and porosity parameters in comparison to tested catalytic filtration materials, making it more suitable for adsorption and catalytic manganese oxidation.
\end{abstract}

\section{Introduction}

Traditional technology of groundwater treatment consists of aeration followed by filtration. The iron and manganese removal occurs due to heterogenic and autocatalytic oxidation in catalytic-oxidative filtration beds. The catalyser is manganese dioxide - the product of $\mathrm{Mn}$ (II) oxidation.

Most common filtration material is silica sand. Clean fresh silica sand has no catalytic properties becoming an auto-activated material after covering grains with manganese oxides. This permanent oxides contact layer may be created with no chemical dosage $[1,2]$. The rippening of filtration material is often supported with biological oxidation process [3-6].

Another type of filtration materials are natural catalytic filter media (e.g. Pyrolox, Gabon manganese ore). This type of media is often use in small WTPs. Often these media loose in time the high efficiency in manganese removal and new steady state of dynamic balance has to be reached [7].

There are on the market artificially activated oxidative media - industrial products, manufactured with patented technology. It may be expected that the manganese oxidation catalysers of different filtration materials have different characteristics. The difference appear in chemical composition, microstructure parameters and polymorphic forms present compounds $[8,9]$.

Manganese oxidation from the bivalent to quadrivalent form undergo on different pathways. One of the possible pathways of manganese oxidation is given in Fig. 1.

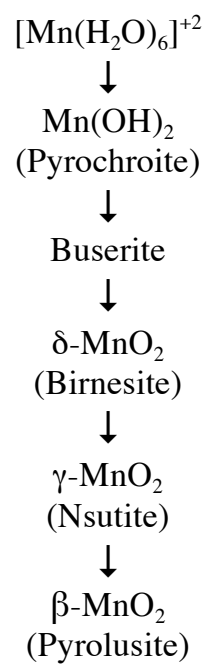

Fig. 1. Manganese oxidation pathways [10].

Pyrolusite is the most stable form of manganese dioxide, It occurs naturally or is formed with use of chemical oxidants [6]. Pyrolusite has adsorption capacity to $\mathrm{Mn}$ (II) but does not have auto-catalytical properties [11]. Birnessite is the manganese oxide with the valency equal to $3.5-3.9$, easily undergoes red-ox reactions, takes part in ion exchange, has high adsorption capacity for manganese, ensuring conditions for auto-catalytical oxidation [11]. Birnessite is a product of auto-catalytical

Corresponding author: joanna.jez-walkowiak@put.poznan.pl 
reactions of manganese oxidation taking place in systems of aeration and rapid filtration, without chemical dosage [2,11].

The manganese oxidation, taking place in filter media, is a heterogenic process on the surface of grains. An important factor affecting the adsorption of manganese on contact layer is the surface charge. The values of isoelectric point for quartz and manganese dioxide are shown in Table 1.

Natural groundwater usually has $\mathrm{pH}$ within the range of 5.5-7.5. At this $\mathrm{pH}$ surfaces of silica sand grains have negative charge. Higher negative charge in lower $\mathrm{pH}$ of birnessite $\left(\delta-\mathrm{MnO}_{2}\right)$ than other manganese oxides results in higher potential ability for cations attraction.

Table 1. Point of zero charge for manganese dioxides [10,12].

\begin{tabular}{|c|c|c|}
\hline $\begin{array}{c}\text { Polymorphic } \\
\text { variant of } \mathrm{MnO}_{2}\end{array}$ & Formula & $\begin{array}{c}\text { pH of isoelectric } \\
\text { point }\end{array}$ \\
\hline Hollandite & $\alpha-\mathrm{MnO}_{2}$ & 5.0 \\
\hline Pyrolusite & $\beta-\mathrm{MnO}_{2}$ & 7.2 \\
\hline Nsutite & $\gamma-\mathrm{MnO}_{2}$ & 5.6 \\
\hline Birnessite & $\delta-\mathrm{MnO}_{2}$ & 2.8 \\
\hline Quartz & $\mathrm{SiO}_{2}$ & 2.0 \\
\hline
\end{tabular}

The time and effects of auto-activation of media for manganese removal depend on the microstructure prameters of grains filter media. Investigation of specific surface and pore volume allows determination of the potential ability of the catalyser for manganese adsorption and further auto-catalytic Mn oxidation.

\section{Goal and scope of the research}

The aim of this work is to determine the properties of contact layers of grains in different type of filter media in term of their suitability for catalytical manganese oxidation and auto-activation for manganese removal from groundwater.

Following oxidative filtration materials were investigated (Table 2):

- auto-activated silica sand taken from full-scale filters (oxide coated filter media),

- Pyrolox - manganese ore - natural material,

- Hydrolit - artificially activated material.
As a reference two natural, not chemically active, materials were tested:

- clean silica sand,

- clean chalcedonite.

\section{Methods}

For catalytic contact layer of filter media grains investigation the following methods were used:

- energy dispersive spectroscopy - EDAX, coupled with SEM,

- Raman spectroscopy,

- mercury and helium porozymetry method.

Raman spectrometry was done with Renishaw apparatus. The SEM-EDAX analysis was done with Quanta FEG 250 (FEI) Microscope coupled with EDS Octane II Silicon Drift Detector (EDAX).

To determine the chemical composition of catalysts the energy dispersive spectroscopy EDAX, coupled with SEM was used. Weight shares of predominant elements were analysed using Microscope Quanta FEG 250 (FEI) with EDS Octane II Silicon Drift Detector (EDAX).

For the research on the identification of different polymorphic forms of oxides of the investigated catalysts, the method of $\mu$-Raman spectroscopy was used. The non-polarised Raman spectra of filtration materials were recorded in the backscattering geometry using a Via Renishaw micro-Raman system. All spectra were recorded in the range of 100 to $2000 \mathrm{~cm}^{-1}$. As an excitation light, the green line of argon laser operating at $514.5 \mathrm{~nm}$ (three accumulations of each spectra) was used. A laser beam was focused on the sample through the long working distance of the $50 \times / 0.5$ objective. The spatial resolution of the Raman spectra was about $2 \mu \mathrm{m}$. The power of the laser beam was less than $5 \mathrm{~mW}$. All measurements were performed at room temperature. The crystalline structure of the catalytic contact layer in the manganese removal zone as well as silica sand beds were examined using the method of X-ray powder diffractometry (XRD). Examinations consisted of a comparison of diffraction diagrams obtained in Brucker D8Advance diffractometer for the analysed samples and the reference diagrams available in specialised databases [13]. The internal structure parameters pore volume and specific surface area was determined with the nitrogen adsorption method with a Tristar II 3020 apparatus.

Mercury porosimetry analysis is the progressive

Table 2. Element composition of tested materials.

\begin{tabular}{|c|c|c|c|c|c|c|c|c|c|c|}
\hline \multirow{2}{*}{ Investigated material } & \multicolumn{9}{|c|}{ Weight shares of elements, in \% } \\
\cline { 2 - 13 } & $\mathbf{F e}$ & $\mathbf{M n}$ & $\mathbf{O}$ & $\mathbf{S i}$ & $\mathbf{C a}$ & $\mathbf{A l}$ & $\mathbf{K}$ & $\mathbf{M g}$ & $\mathbf{S}$ & $\mathbf{P}$ \\
\hline Chalcedonite & 0.6 & - & 61.5 & 33.3 & 0.36 & 3.54 & 0.32 & - & 0.32 & - \\
\hline Silica sand & 0.17 & - & 60.7 & 37.4 & - & 1.42 & 0.24 & - & - & - \\
\hline $\begin{array}{c}\text { Catalyser - iron } \\
\text { removal zone }\end{array}$ & 30.1 & 17.5 & 45.1 & 1.57 & 3.75 & 1.15 & - & - & 0.08 & 0.56 \\
\hline $\begin{array}{c}\text { Catalyser - manganese } \\
\text { removal zone }\end{array}$ & 17.0 & 18.5 & 56.6 & 1.06 & 3.27 & 3.32 & - & - & - & 0.28 \\
\hline Pyrolox & 3.66 & 48.95 & 40.6 & 1.84 & - & 2.73 & 1.52 & - & - & 0.07 \\
\hline Hydrolit & 1.4 & 36.57 & 36.88 & 3.93 & 15.22 & 3.33 & 0.71 & 1.46 & 0.47 & 0.02 \\
\hline
\end{tabular}


intrusion of mercury into a porous structure under stringently controlled pressures. From the pressure versus intrusion data, the instrument generates volume and size distributions using the Washburn equation.. Clearly, the more accurate the pressure measurements, the more accurate the resulting pore size data.

Mercury porosity analysis of tested materials was done using AutoPore9220 apparatus by Micrometrics. Applied instrument allows to determine the pore distribution in the range of pore diameter from 0.003 to $500 \mu \mathrm{m}$, with applied maximum pressure of $60000 \mathrm{psi}$. The helium porosimeter due to penetrating properties of helium allows to determine the submicropore structute of tested materials. It enables to precise measure of specific density of samples.

The sample of filtration material (of given mass-M and given volume $\mathrm{V}_{\text {ext }}$ ) is placed into calibrated chamber of helium porosimeter and then helium is introduced. From the amount of introduced helium the volume of structure of filtration material $-\mathrm{V}_{\text {structure }}$ is calculated. The total open porosity coefficient $\mathrm{m}_{\text {open }}$ is calculated according to the formula (1):

$$
\mathrm{m}_{\text {open }}=\left(\mathrm{V}_{\text {ext }}-\mathrm{V}_{\text {structure }}\right) / \mathrm{V}_{\text {ext }}
$$

Next the same sample is introduced into mercury porozymeter and the bulk density $\rho_{\mathrm{b}}$ is determined taking into account the volume of mercury $-\mathrm{V}_{\mathrm{Hg}}$ (non-moisten liquid) driven out by the porous sample.

$$
\rho_{\mathrm{b}}=\mathrm{M} / \mathrm{V}_{\mathrm{Hg}}
$$

The dynamic porosity is calculated taking into account the volume of mercury introduced into the sample under pressure up to $60000 \mathrm{psi}$. The calculation of pores volume includes only the volume of pores available for mercury: $0,01-360 \mu \mathrm{m}$. The value of dynamic porosity is smaller than the value of open porosity.

\section{Results and discussion}

The photographs of investigated materials' surfaces using Raman spectrometer and scanning electron microscope show that the auto-activated contact layer is not homogenous and consists of centres of iron and manganese oxides.
The comparison of not-chemically active materials shows the more developed surface structure of chalcedonite than silica sand. This creates better suitability of chalcedonite for autoactivation for manganese removal from groundwater [2].

In Table 2 the element composition of investigated media are presented. The data were obtained using apparatus EDAX [14].

The EDAX results (Table 2) indicate, that:

- silica sand and chalcedonite are chemically homogenous, mostly consisting of $\mathrm{SiO}_{2}$,

- catalyser of iron removal zone consists of iron $(30.1 \%)$, manganese $(17.5 \%)$, oxygen $(46.0 \%)$, calcium $(3.75 \%)$, indicating presence of iron and manganese oxides in the mass of catalyser.

- catalyser of manganese removal zone consist of manganese $(18.5 \%)$, iron (17\%), calcium $(3.25 \%)$. The presence of iron and calcium in this catalyser lowers catalytical activity of contact layers.

- in Pyrolox manganese dioxide is the main constituent,

- Hydrolit is a mixture of manganese iron, calcium and magnesium compounds.

For identification of compound structure of investigated media the method of $\mu$-Raman spectroscopy was used. The method is based on comparison of tested materials spectra and reference spectra. In Table 3 the values of characteristic wavenumber for iron, manganese and quartz oxides expected in contact layers are presented. For the investigation the Renishaw spectroscope was used. Raman spectra of tested materials and catalysers are presented in Fig. $2-7$.

The Raman spectrum of the chalcedonite and silica sand samples, presented in Figures 2 and 3 respectively have the following Raman bands: 127, 206, $464 \mathrm{~cm}^{-1}$. The same values of characteristic wavenumbers can be found in the reference spectrum of quartz (Table 3). Silica sand and chalcedonite are filtration materials with the structure of pure quartz.

Comparison of Raman spectrum for the iron removal zone with the reference plot of characteristic wavenumber (Table 3, Fig. 4) of iron oxides, indicated the presence of hematite $\alpha \mathrm{Fe}_{2} \mathrm{O}_{3}$ and maghenite $\gamma \mathrm{Fe}_{2} \mathrm{O}_{3}$ [15].

In manganese removal zone the presence of birnessite, was proved (Table 3, Fig. 5).

Table 3. Raman shifts for silica and iron and manganese oxides $[11,15,16]$.

\begin{tabular}{|c|c|c|c|c|c|c|}
\hline Compound & \multicolumn{7}{|c|}{ Wavenumber, $\left[\mathbf{c m}^{-\mathbf{1}}\right]$} \\
\hline Quartz, $\mathrm{SiO}_{2}$ & 127 & 206 & 464 & & & \\
\hline Maghemite $\gamma \mathrm{Fe}_{2} \mathrm{O}_{3}$ & 350 & 512 & 665 & 730 & & \\
\hline Hematyte $\alpha \mathrm{Fe}_{2} \mathrm{O}_{3}$ & 265 & 300 & $345-395$ & 515 & $645-670$ & 715 \\
\hline Birnessite $\delta-\mathrm{MnO}_{2}$ & $495-505$ & $570-575$ & $635-655$ & & & \\
\hline Pyrolusite $\beta-\mathrm{MnO}_{2}$ & 538 & 665 & & & & \\
\hline Nsutite $\gamma-\mathrm{MnO}_{2}$ & 379 & 491 & 520 & 572 & 631 & 738 \\
\hline Ramsdelite & 294 & 518 & 580 & 630 & 740 & \\
\hline
\end{tabular}




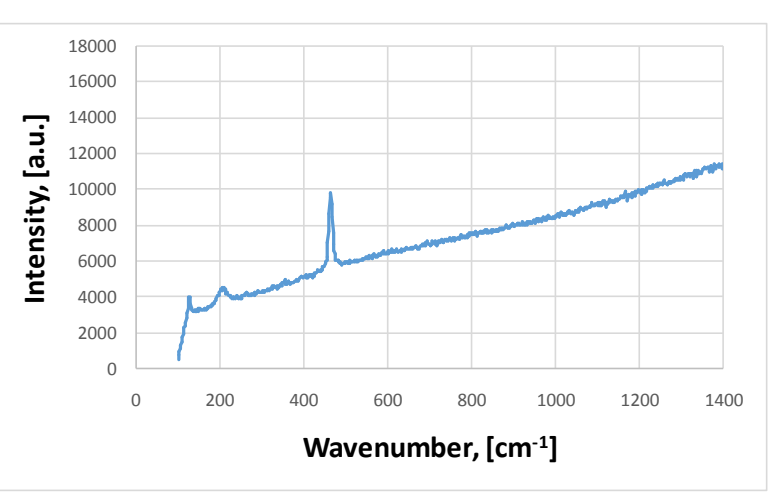

Fig. 2. Raman spectrum for chalcedonite.

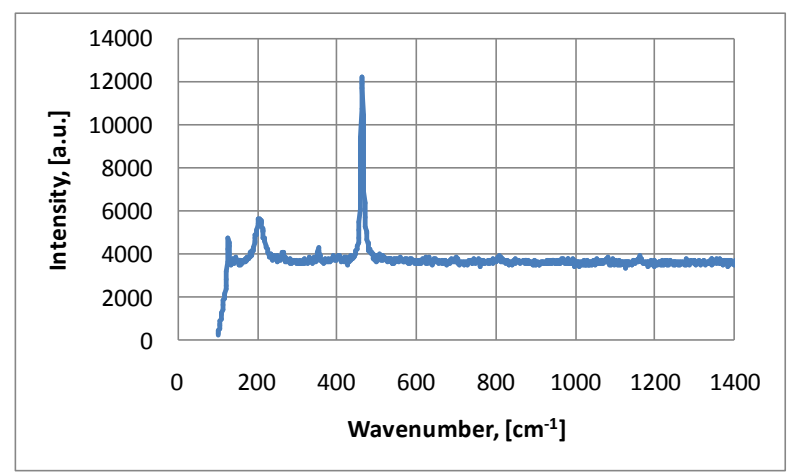

Fig. 3. Raman spectrum for silica sand.

In Pyrolox the presence of manganese oxides in the form of pyrolusite, ramsdelite and nsutite (Table 3, Fig. 6) were found.

Raman spectrum of Hydrolit indicated manganese dioxide in the form of pyrolusite (Table 3, Fig. 7).

In Table 4 porozymetry parameters obtained with mercury porozymetry method and helium porosity method are presented. AutoPore IV 9500 used in investigation allows to determine the pore structure within the range of pore diameter $0.003-500 \mu \mathrm{m}$.

Manganese removal zone catalyser has the high value of specific surface area $124.75 \mathrm{~m}^{2} / \mathrm{g}$. The low value of bulk density $0.652 \mathrm{~g} / \mathrm{cm}^{3}$ correlates with high value of total porosity $80.552 \%$. Established porosity parameters allow to consider manganese removal zone catalyser as a porous material with good adsorption properties. The specific surface area of Pyrolox and Hydrolit are few times lower than manganese removal zone catalyser.

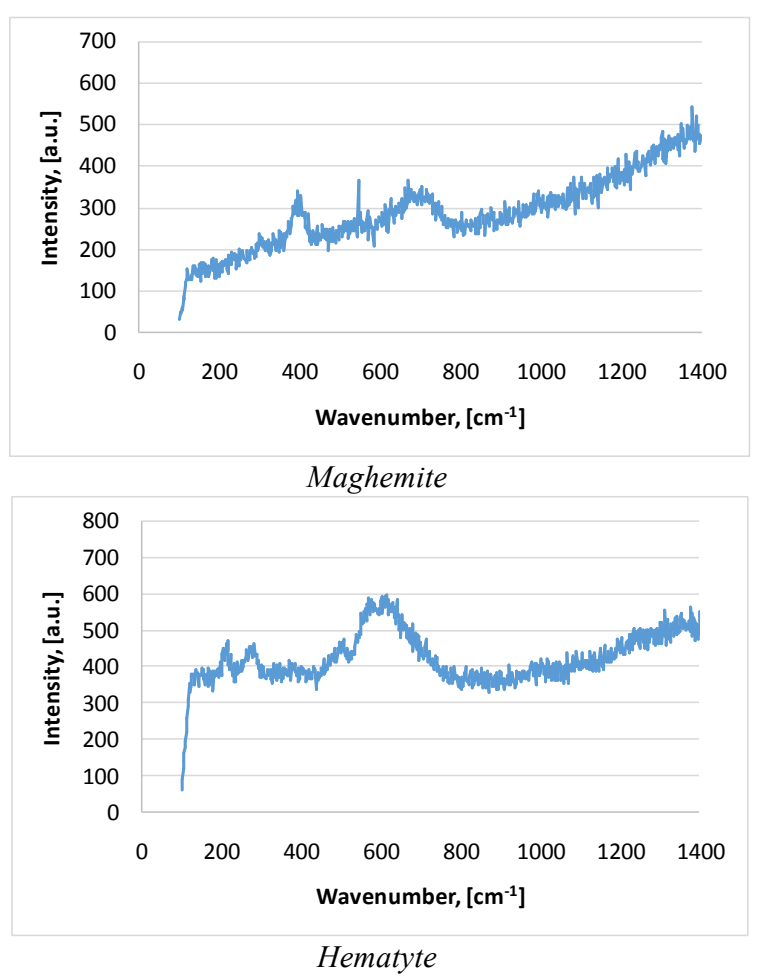

Fig. 4. Raman spectra for iron removal zone.

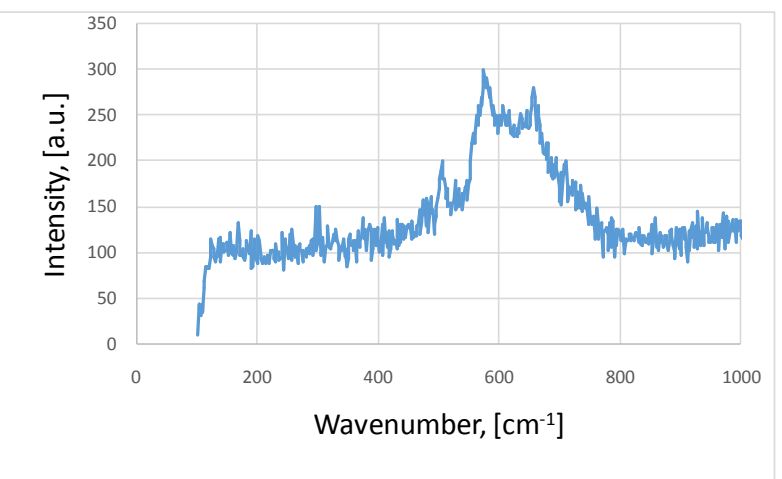

Fig. 5. Raman spectrum for manganese removal zone.

The lowest value of specific surface area have silica sand. On the other hand the specific surface area of chalcedonite is almost two times higher than Pyrolox and Hydrolit and 200 times higher than silica sand. It gives the evidence of better properties of chalcedonite to autoactivation for manganese removal from groundwater [2].

Table 4. Porozymetry parameters obtained with AutoPore apparatus.

\begin{tabular}{|c|c|c|c|c|c|}
\hline \multirow{2}{*}{ Material } & Mass density & $\begin{array}{c}\text { Total open } \\
\text { porosity }\end{array}$ & Bulk density & $\begin{array}{c}\text { Dynamic } \\
\text { porosity }\end{array}$ & $\begin{array}{c}\text { Specific surface } \\
\text { area }\end{array}$ \\
\cline { 2 - 6 }$[\mathbf{\%}]$ & {$[\mathbf{\%}]$} & {$\left[\mathbf{m}^{2} / \mathbf{g}\right]$} \\
\hline $\begin{array}{c}\text { Manganese removal zone } \\
\text { of rippened silica sand } \\
\text { bed }\end{array}$ & 3.335 & 80.552 & 0.652 & 72.056 & 124.75 \\
\hline Pyrolox & 4.03 & 23.81 & 3.08 & 20.35 & 2.58 \\
\hline Hydrolit & 2.92 & 13.01 & 2.49 & 11.94 & 2.06 \\
\hline Silica sand & 2.64 & 5.15 & 2.48 & 5.00 & 0.02 \\
\hline Chalcedonite & 2.63 & 35.68 & 1.71 & 29.73 & 4.74 \\
\hline
\end{tabular}



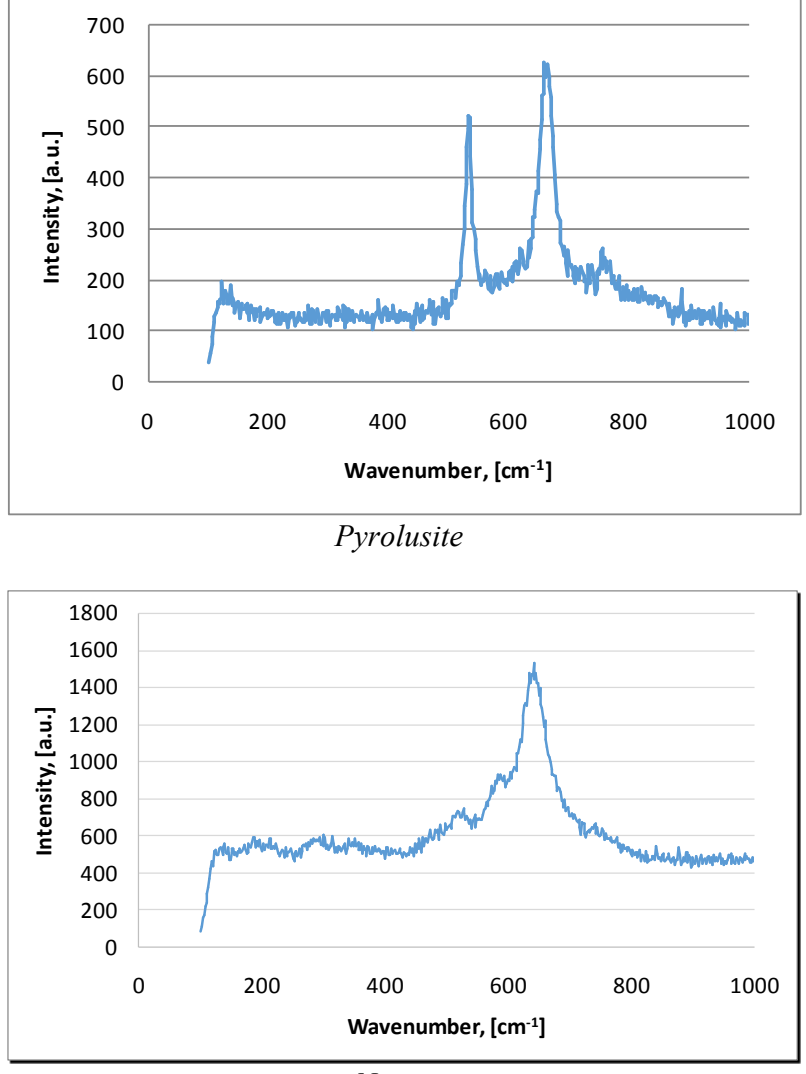

Nsutite

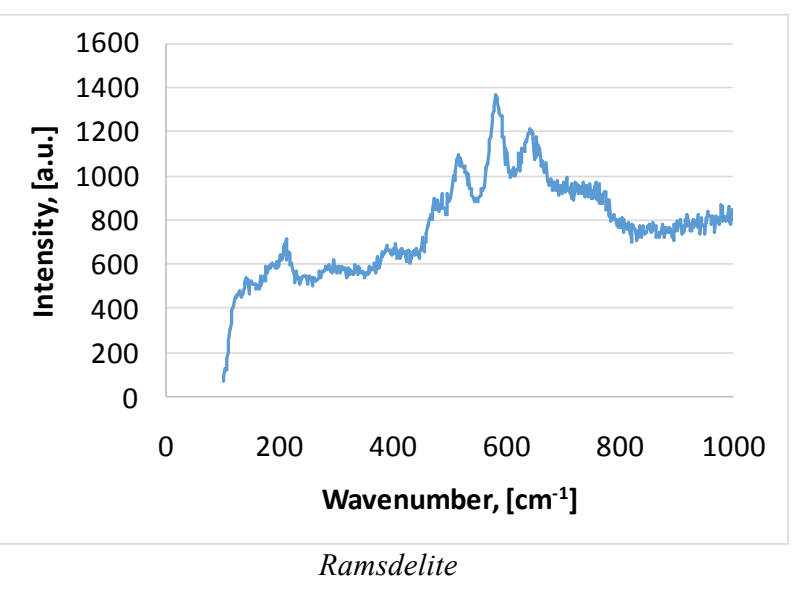

Fig. 6. Raman spectra for Pyrolox.

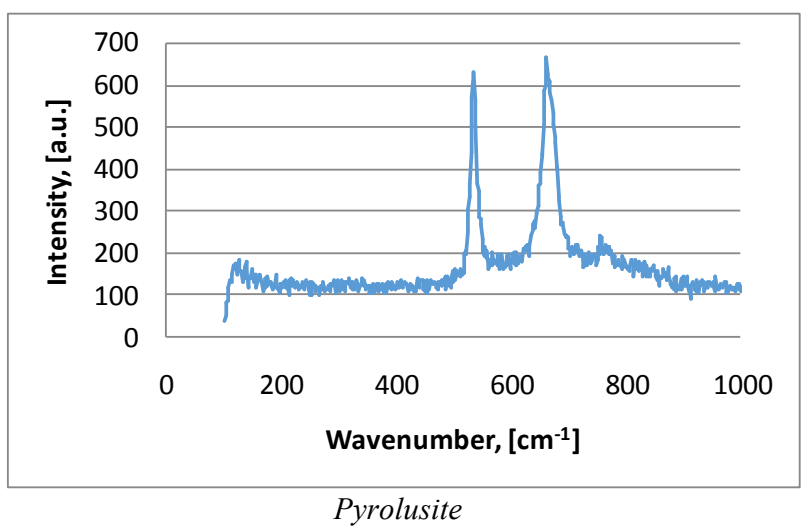

Fig. 7. Raman spectrum for hydrolit.

\section{Conclusions}

In the described investigation on catalysers for catalytic manganese oxidation, the methods of instrumental analysis were used. The obtained data allowed:

- determination of elements' shares and chemical composition of the investigated catalysers,

- determination of microstructure parameters e.g. specific surface area and porosity of the contact catalytical layer of tested media.

The analysis of catalyser of manganese removal zone pointed that this material is the most capable for effective manganese removal from groundwater in the process of heterogenic autocatalytic oxidation in filter bed. This capability comes from chemical composition of catalyser from auto-activated beds and because of high content of manganese dioxide in the form of birnessite, $\mathrm{MnO}_{1.3+1.9}$ - not fully oxidized manganese dioxide with deficiency of oxygen. Such oxide becomes a semi-conductor able to transport electrons, guarantying good efficiency of heterogeneous reaction.

Catalyser from iron removal zone contains the iron oxides in the form of $\alpha \mathrm{Fe}_{2} \mathrm{O}_{3}$ - hematite and $\gamma \mathrm{Fe}_{2} \mathrm{O}_{3}-$ maghemite.

The analysis of microstructure also proof the capability of auto-activated catalysers for effective adsorption of manganese from treated water due to high values of the specific surface area and pore volume, measured by Autopore apparatus. Catalyser of the manganese removal zone has a specific surface area $124.75 \mathrm{~m}^{2} / \mathrm{g}$ and total porosity $80.55 \%$.

In Pyrolox the manganese dioxides were detected in the form of ramsdelite, nsutite and pyrolusite. This bed is characterised by much lower specific surface area $2.58 \mathrm{~m}^{2} / \mathrm{g}$ in comparison to auto-activated catalyser.

Artificially activated Hydrolit is a mixture of manganese, iron, calcium and magnesium compounds. This bed is characterised by the low specific surface area of $2.06 \mathrm{~m}^{2} / \mathrm{g}$ determined with mercury porosimetry method.

Investigation of two not-chemically active materials demonstrate the higher chalcedonite potential for manganese removal auto-activation due to higher, in comparison to silica sand, values of microstructure parameters.

Further research on relationships between the characteristic of catalysers and technological effects of groundwater treatment should be conducted. It will help the evaluation of mechanisms of heterogenous, catalytic manganese oxidation in filtration bed.

The authors would like to express their thanks for the financial support from research project 01/13/DSPB/0857.

\section{References}

1. J. Jeż-Walkowiak, Z. Dymaczewski, J. Wat. Sup. Res. Tech. AQUA 61, 6 (2012)

2. J. Jeż-Walkowiak, Wpływ właściwości złóż filtrów pospiesznych na efekty technologii odżelaziania $i$ 
odmanganiania wód podziemnych (Wyd. PP, Poznań, 2016)

3. P. Mouchet, AWWA J. 84, 4 (1992)

4. K. Olańczuk-Neyman, R. Bray, Pol. J. Env. Stud. 9, 2 (2000)

5. R. Bray, K. Olańczuk-Neyman, Wat. Sci. Tech. Wat. Sup. 1, 2 (2001)

6. R. Bray, II Congress of Environmental Engineering, Lublin, Poland, Monografie PAN, vol.32, (2005)

7. J. Jeż-Walkowiak, Z. Dymaczewski, A. SzusterJaniaczyk, A.B. Nowicka, M. Szybowicz, Water 9, 498 (2017)

8. J. Jeż-Walkowiak, Intensyfikacja procesu odżelaziania odmanganiania wód podziemnych $w$ złożach oksydacyjnych filtrów pospiesznych (PhD Th., 2000)

9. J. Jeż-Walkowiak, Z. Dymaczewski, Ł. Weber, J. Wat. Sup. Res. Tech. AQUA 64, 1 (2015)

10. W. Stumm, J.J. Morgan, Aquatic Chemistry, Chemical Equilibria and Rates in Natural Waters, Third edition (Wiley Interscience, 1996)

11. J.H. Bruins, B. Petrusevski, Y.M. Slokar, J.C. Kruithof, M.D. Kennedy, Des. Wat. Tr. 55, 7 (2015)

12. M. Kosmulski, Surface charging and points of zero charge, (CRC Press, Tylor\&Fracis Group, 2009)

13. S. Jędrychowska, Możliwości wykorzystania spektroskopii ramanowskiej $w$ branży naftowej, $c z$. I, (Nafta-Gaz, 2012).

14. A. Barbacki, Mikroskopia elektronowa, (Wyd. PP, Poznań, 2007)

15. M. Szybowicz, M. Koralewski, J. Karoń, L. Melnikova, Acta Phys. Pol. O. Acc. 127, 2 (2015)

16. C. Julien, M. Massot, R. Baddour-Hadjeans, S. Franger, S. Bach, J.P. Pereira-Ramos, Sol. State Ion. 159 (2003). 